\title{
Melting Curve Analysis of Aptachains: Adenosine Detection with Internal Calibration
}

\author{
Chenze Lu 1,2,3, Christine Saint-Pierre 2 , Didier Gasparutto ${ }^{2}$, Yoann Roupioz ${ }^{2} \mathbb{B}$, Corinne Ravelet ${ }^{3}$, \\ Eric Peyrin ${ }^{3}$ (D) and Arnaud Buhot ${ }^{2, *(\mathbb{D})}$ \\ 1 College of Life Sciences, China Jiliang University, Hangzhou 310018, China; chenzelu@cjlu.edu.cn \\ 2 University Grenoble Alpes, CEA, CNRS, IRIG, SyMMES, F-38000 Grenoble, France; \\ christine.saint-pierre@cea.fr (C.S.-P.); didier.gasparutto@cea.fr (D.G.); yoann.roupioz@cea.fr (Y.R.) \\ 3 University Grenoble Alpes, CNRS, DPM, F-38000 Grenoble, France; \\ corinne.ravelet@univ-grenoble-alpes.fr (C.R.); eric.peyrin@univ-grenoble-alpes.fr (E.P.) \\ * Correspondence: arnaud.buhot@cea.fr; Tel.: +33-4-38-78-38-68
}

Citation: Lu, C.; Saint-Pierre, C.; Gasparutto, D.; Roupioz, Y.; Ravelet, C.; Peyrin, E.; Buhot, A. Melting Curve Analysis of Aptachains:

Adenosine Detection with Internal Calibration. Biosensors 2021, 11, 112. https://doi.org/10.3390/bios11040112

Received: 1 March 2021

Accepted: 6 April 2021

Published: 8 April 2021

Publisher's Note: MDPI stays neutral with regard to jurisdictional claims in published maps and institutional affiliations.

Copyright: (c) 2021 by the authors. Licensee MDPI, Basel, Switzerland. This article is an open access article distributed under the terms and conditions of the Creative Commons Attribution (CC BY) license (https:// creativecommons.org/licenses/by/ $4.0 /)$.

\begin{abstract}
Small molecules are ubiquitous in nature and their detection is relevant in various domains. However, due to their size, sensitive and selective probes are difficult to select and the detection methods are generally indirect. In this study, we introduced the use of melting curve analysis of aptachains based on split-aptamers for the detection of adenosine. Aptamers, short oligonucleotides, are known to be particularly efficient probes compared to antibodies thanks to their advantageous probe/target size ratio. Aptachains are formed from dimers with dangling ends followed by the split-aptamer binding triggered by the presence of the target. The high melting temperature of the dimers served as a calibration for the detection/quantification of the target based on the height and/or temperature shift of the aptachain melting peak.
\end{abstract}

Keywords: split-aptamers; small molecule detection; aptachain self-assembly; melting temperature; calibration/normalization

\section{Introduction}

The detection of small molecules plays an important role in various fields like food safety, environmental control, diagnosis, etc. [1-5]. Antibodies, the most commonly used probes in biosensors, are generally difficult to raise against such small targets, i.e., with molecular weight lower than $1000 \mathrm{Da}$. On the other hand, aptamers, single stranded oligonucleotides specifically selected against their target by the Systematic Evolution of Ligands by EXponential enrichment (SELEX) method, are interesting alternative probes [6,7]. Due to their in vitro selection method, ease of synthesis and chemical functionalization, low cost and simple incorporation in biosensors, aptamers have emerged as a new and competitive recognition element for various applications in the past two decades [8-13]. In the particular case of small molecule detection, the advantages of aptamers over antibodies are even more crucial [14-19]. Due to their reversible folding in a particular 3D conformation, they exhibit a binding pocket with strong affinity and selectivity towards small targets while the large size of antibodies compared to the targets confers them a comparative disadvantage.

Nonetheless, the small size of the target molecules and their low concentrations in the solution represent the main challenges in developing biosensors for their detection. Indirect signal amplification is often required in the development of novel label-free sensing methods due to the small signal obtained from the direct binding of the small targets to the probes. Nanoparticle-based strategies are often used to circumvent this problem. Many examples can be found in the literature where molecular probes are covalently bound or adsorbed to metal (usually gold) substrates or nanoparticles [20-29]. However, the preparation of such molecular architectures involves complex functionalization procedure 
and has a high cost in the production and modification of the nanoparticles. Recently, questions arose about the use of adsorbed adenosine aptamers on nanoparticles or graphene as a biosensor strategy [30]. Furthermore, in homogenous phase detection, any change in the probe concentration and/or in sample content $(\mathrm{pH}$, salt concentration...) generally led to variability in the detection method [31-33]. We propose a homogenous phase detection method in which aptamer probes are not immobilized on any surface but still provide a noticeable signal for detection with an internal control suitable for calibration and/or normalization.

The detecting system is based on the self-assembly of 1D DNA chains formed by bi-functional oligonucleotides forming double stranded dimers on one hand and splitaptamer sequences on the other hand. The use of the hybridization chain reaction (HCR) forming such self-assembled 1D DNA chains for signal amplification has been widely developed in recent years [34-40]. However, its use with aptamer recognition to form what are called aptachains, is still in its infancy [3,41-44]. In our case, the adenosine target served as the trigger for thermodynamic control of the linear DNA nanostructure formation in solution.

In order to follow the various steps of the aptachain self-assembly, we focused on melting curve analysis obtained from UV absorbance at $260 \mathrm{~nm}$. Thanks to nucleic acid's hyperchromic property, UV monitoring has been extensively used to determine the melting profile of DNA duplexes or to prove the existence of targets [45-48]. The change in the wavelength of the absorbed light is also used to analyze the interactions that take place in the solution [49-53]. In our method, the melting curve of the aptachain structures obtained from UV spectroscopy is used to detect the change in the binding strength of the splitaptamers with the target. The melting peak and temperature of the split-aptamer bindings are shown to be directly related to the amount of adenosine target present in the solution, thus, allowing its detection and potential quantification. UV spectroscopy is commonly used as a supplementary method to confirm the change in the binding strength, but it is rarely proposed as a detection method because measurements are influenced by the buffer composition or aptamer concentration. For this reason, the reading of the melting peak or temperature could not determine the presence of the target directly. In our study, the building of the aptachains from oligonucleotides containing hybridizing dimer moieties provided an internal reference with a well-defined high melting temperature. Thus, at low temperature, the targets trigger the split-aptamer self-assembly and, at high temperature, the hybridization of the dimers serves as an internal reference providing two different peaks in the melting curve analysis. This approach has enabled the direct detection and quantification of the target.

\section{Materials and Methods}

\subsection{Reagents and Oligonucleotides}

The reagents used for preparing the buffer as well as adenosine and guanosine were purchased from Sigma-Aldrich (Saint Quentin Fallavier, France). The oligonucleotide sequences (see Table 1) were purchased from Eurogentec (Angers, France). The buffer in which the oligonucleotides were mixed consisted of $10 \mathrm{mM}$ HEPES, $5 \mathrm{mM} \mathrm{MgCl}$, and $150 \mathrm{mM} \mathrm{NaCl}$, and its $\mathrm{pH}$ was set at 7.4 with $\mathrm{HCl}$ and $\mathrm{NaOH}$.

\subsection{Oligonucleotides Sequence Design}

We tested five sequence designs with different binding strengths for the split aptamers as well as a full aptamer as reference. The number of base pairs hybridized in the splitaptamer dangling ends controlled their binding strengths. The DNA sequences near the binding pocket of the split-aptamer are shown in Scheme 1. The sequences are named by the number of complementary base pairs in the split-aptamer dangling ends (blue sequences in Table 1) next to the binding pocket (black sequences). For example, SA3-5A/B illustrated in Scheme 1 had three base pairs hybridized on the left side and five on the right side (blue sequences in Table 1) of the binding pocket. While SA stands for split-aptamer, 
the final letters A or B relate to an additional Zip sequence (red sequences in Table 1) on the $3^{\prime}$ end, which are complementary to each other and allow the dimer formation (see illustration in Scheme 2). The detailed sequences of these five designs are displayed in Table 1 along with the Apta6 sequence corresponding to a full adenosine aptamer, which will be used as a reference. The binding strength near the adenosine pocket of the five sequence designs is expected to increase with the number of hybridizing base pairs. The binding of the split-aptamer will be called an 'aptamer bridge' in the following. To decrease the affinity of the aptamer bridge of the least stable sequences, a non-complementary GAG sequence has been added (Yellow in Scheme 1).
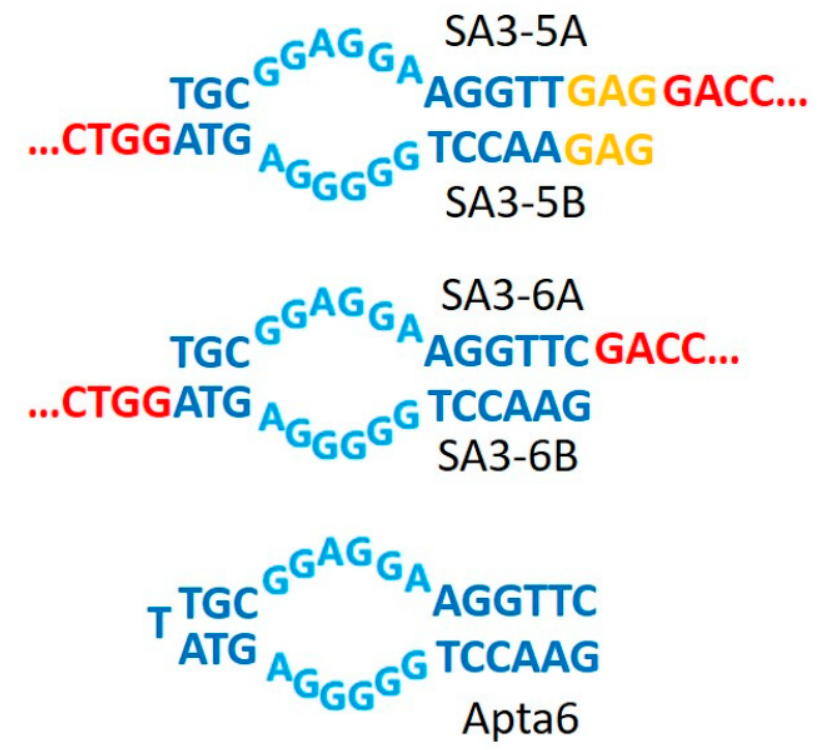
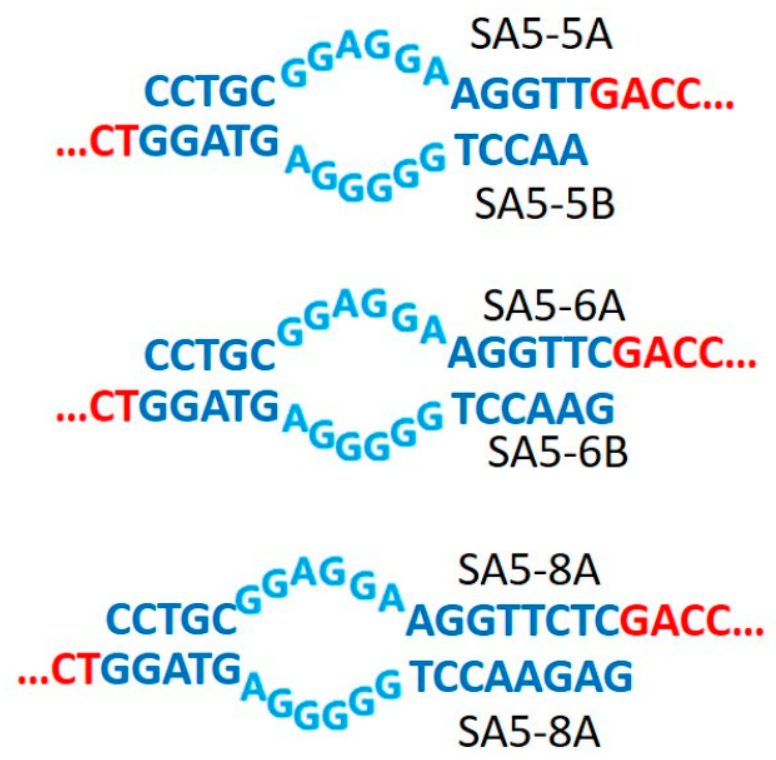

Scheme 1. Split aptamer sequence designs. The dimers are composed of two sequences, SAX-YA and SAX-YB sorted by the number of base pairs hybridized on the left $(X)$ and right $(Y)$ side of the adenosine pocket. SA stands for split aptamer while the final letters A and B are Zip sequences at the $3^{\prime}$ end. Zip sequences A and B are complementary to each other in order to ensure dimer formation at high temperature. The aptachains formed at lower temperature are driven by the hybridization of the split aptamers (split-aptamer bridge) and possibly enhanced by the presence of adenosine (see Scheme 2). SA3-5A/B sequences present a non-complementary sequence GAG (yellow). The full aptamer Apta6 with six hybridizing base pairs at the end of the hairpin was also considered as a reference.

Table 1. Split aptamer sequences with their names (see Scheme 1 for illustration).

\begin{tabular}{cc}
\hline Name & Oligonucleotide Sequences (from $\mathbf{5}^{\prime}$ to $\mathbf{3}^{\prime}$ ) \\
\hline SA3-5A & TGCGGAGGAAGGTTGAGGACCATCGTGCGGGTAGGTAGACC \\
\hline SA3-5B & GAGAACCTGGGGGAGTAGGTCTACCTACCCGCACGATGGTC \\
\hline SA5-5A & CCTGCGGAGGAAGGTTGACCATCGTGCGGGTAGGTAGA \\
\hline SA5-5B & AACCTGGGGGAGTAGGTCTACCTACCCGCACGATGGTC \\
\hline SA3-6A & TGCGGAGGAAGGTTCGACCATCGTGCGGGTAGGTAGACC \\
\hline SA3-6B & GAACCTGGGGGAGTAGGTCTACCTACCCGCACGATGGTC \\
\hline SA5-6A & CCTGCGGAGGAAGGTTCGACCATCGTGCGGGTAGGTAGA \\
\hline SA5-6B & GAACCTGGGGGAGTAGGTCTACCTACCCGCACGATGGTC \\
\hline SA5-8A & CCTGCGGAGGAAGGTTCTCGACCATCGTGCGGGTAGGTAGA \\
\hline SA5-8B & GAGAACCTGGGGGAGTAGGTCTACCTACCCGCACGATGGTC \\
\hline Apta6 & GAACCTGGGGGAGTATTGCGGAGGAAGGTTC
\end{tabular}


A) Aptachain diagram

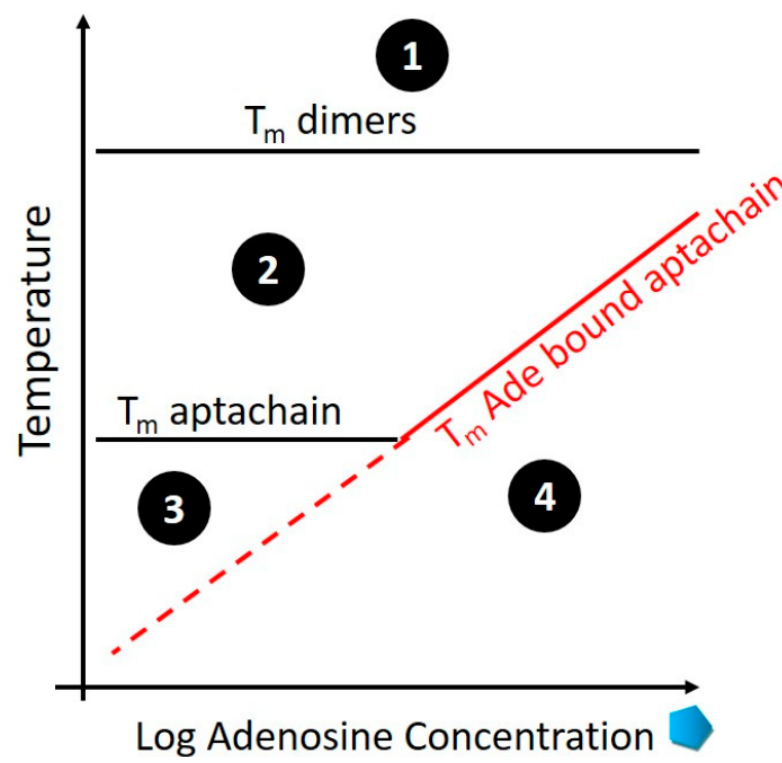

B) Aptachain stages

\section{No complex}

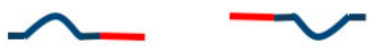

2 Dimers

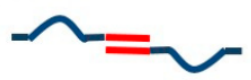

3 Chain without Ade

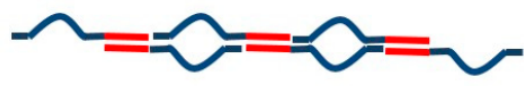

4 Chain with Ade

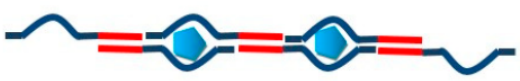

Scheme 2. Illustration of (A) the aptachain phase diagram with the corresponding melting temperatures and (B) the self-assembly stages. The different stages of the aptachain formation are illustrated as a function of the temperature and the adenosine concentration (A). Starting from high temperature (region 1), the dimers form due to the hybridization of the Zip sequences (region 2) at $\mathrm{T}_{\mathrm{m}}$ (dimers). By further decreasing the temperature, aptachains form due to the split-aptamer sequences hybridization independently of the adenosine concentration (region 3). At low adenosine concentration and by further lowering the temperature, adenosine binds to the aptamer pocket (melting temperature: dashed red line leading to region 4). At a high concentration of adenosine, its binding to the aptachains enhances its stability. Consequently, the aptachains form at higher temperatures (melting temperature: full line in red), which are adenosine concentration dependent.

\subsection{UV-Vis Measurements}

The UV measurements were performed on a Cary 100 UV-Vis Spectrophotometer (Agilent, Santa Clara, CA, USA). The sample solutions were obtained by mixing oligonucleotides and adenosine in the buffer solution. The concentrations of oligonucleotides were kept at $0.9 \mu \mathrm{M}$ to maintain a high resolution in the absorption curve (except when otherwise quoted). For each sample solution containing oligonucleotides and adenosine, a reference sample solution was considered by mixing the same amount of adenosine in the buffer without the oligonucleotides. For UV measurements, $1 \mathrm{~mL}$ of sample and reference solutions were injected inside two different cuvettes. The cuvettes were sealed and placed into the chamber slots. UV light at $260 \mathrm{~nm}$ passed through the window of the cuvettes and was analyzed to provide the absorption data. The UV light adsorption was determined by subtracting the absorption of the reference sample from the solution sample to eliminate the influence due to the adenosine absorption at $260 \mathrm{~nm}$. Adenosine concentrations were varied based on the purpose of the tests. Guanosine molecules were used as a negative control to analyze the selectivity $[27,54]$.

Before each melting curve analysis, the samples were heated to $95{ }^{\circ} \mathrm{C}$ for $5 \mathrm{~min}$ and cooled down at room temperature for at least $30 \mathrm{~min}$. During the analyses, a venting system was running to refresh the air inside the chamber and reduce frosting at low temperature. Samples were kept at $15^{\circ} \mathrm{C}$ for $10 \mathrm{~min}$ before the temperature scan was performed. Then, the solutions were heated up to $80^{\circ} \mathrm{C}$ step by step. For every $+0.2^{\circ} \mathrm{C}$ increase in the temperature, the absorbance of UV light was recorded after $1 \mathrm{~min}$ delay. Once the temperature reached $80^{\circ} \mathrm{C}$, the samples were heated to $90^{\circ} \mathrm{C}$ with larger increasing steps of $+0.5^{\circ} \mathrm{C}$. The temperature decrease followed similar temperature steps. The whole temperature cycle was repeated 4 times for each sample. The different heating/cooling rate at high tem- 
perature reduced the evaporation of samples and eliminated its influence on the accuracy and repeatability of the measurement (see experimental data of the 4 temperature scans in Supplementary Information Figure S1). The melting curves were obtained by taking the first derivative of the $260 \mathrm{~nm}$ UV absorbance as a function of temperature. The peak height of the highest melting temperature was set to one for normalization.

\section{Results and Discussion}

\subsection{Aptachain Formation and Melting Curve Analysis through Temperature Scans}

Split-aptamers are obtained from the original anti-adenosine hairpin aptamer (see Apta6 sequence in Scheme 1) by removing a thymine in the middle of the loop [27-29]. This splitting does not strongly affect the affinity towards adenosine since the binding pocket in the middle of the stem is not affected. The split-aptamers (blue in Scheme 2) were combined with oligonucleotide Zip (red). A 24-mer Zip sequence was added to the $3^{\prime}$ end of the split-aptamer while its complementary sequence was added to the other half of the split aptamer couple in order to induce dimer formation (transition 1 to 2 in Scheme 2) at high temperature.

By decreasing the temperature further, the dangling ends of the dimers hybridize to form bridges with the pocket available for adenosine binding. Without adenosine in the solution, the formation of those bridges leads to the formation of aptachains (transition from region 2 to 3 in Scheme 2). In the presence of adenosine, its binding to the pocket stabilizes the bridges and thus the aptachain formation. Indeed, we expect that by increasing the adenosine concentration, a larger amount of targets will bind to the aptamer pocket leading to an increase of the melting temperature (transition from region 2 to $4^{\prime}$ in Scheme 2). At low adenosine concentrations, we may expect that the adenosine binding will occur at temperatures below the formation of the aptachains (transition from region 3 to 4 ) thus not affecting the experimental value of the melting temperature for aptachain formation. However, in this case, we still expect that the binding of the targets will affect the melting peak. More importantly, the melting peak for the dimer formation should not be affected by the presence of adenosine and, thus, it may serve as an internal control for normalization of the melting curves.

\subsection{Impact of Split-Aptamer Design on Aptachain Formation}

In order to explore the aptachain formation, we designed five different split-aptamer couples along with similar Zip sequences (SA3-5A/B, SA3-6A/B, SA5-5A/B, SA5-6A/B, and SA5-8A/B). We expected to enhance the stability of the aptamer bridges by increasing the number of hybridized base pairs. The melting curves were obtained for those five designs along with the reference aptamer (Apta6) without adenosine (Figure 1). In order to assess the impact of the presence of adenosine, we also analyzed the melting curves in the presence of a large excess of the target $(100 \mu \mathrm{M})$. In all cases, oligonucleotides concentrations were set at $0.9 \mu \mathrm{M}$. In each of the cases, four different scans were carried out to estimate the reproducibility. No evaporation effect was observed (Figure S1 in Supplementary Information).

First, as expected, we observe a similar high temperature melting peak for all five designs at $\mathrm{T}_{\mathrm{m}}=75 \pm 2{ }^{\circ} \mathrm{C}$, which is compatible with the dimer formation. Indeed, the melting temperature for the Zip sequences is expected at $77.3^{\circ} \mathrm{C}$ by the Mfold software [55]. Furthermore, for the full aptamer, the melting peak at high temperature is absent. Secondly, a first melting peak for most of the designs is observed at a lower temperature and is reminiscent of the aptachain formation. Only the dimer SA3-5A/B does not display the first peak corresponding to the aptachain formation in absence of adenosine. The aptamer bridge for this design, which is the least stable of all the designs considered, may explain this lack of aptachain formation. In fact, we added a non-complementary GAG on both sequences in order to further destabilize the aptamer bridge. What is interesting to notice is that the presence of adenosine has an important impact for this particular design since a low temperature melting peak is observed at $\mathrm{T}_{\mathrm{m}}=28^{\circ} \mathrm{C}$ in presence of $100 \mu \mathrm{M}$ of adenosine. 
We also performed gel electrophoresis with a large amount of adenosine $(1 \mathrm{mM})$ without noticing any chain formation (see Supplementary Information Figure S2). We may expect that the aptamer bridges are not sufficiently stable to support gel migration since the formation of DNA chains was confirmed by gel electrophoresis for self-complementary dimers (Figure S2).

a)

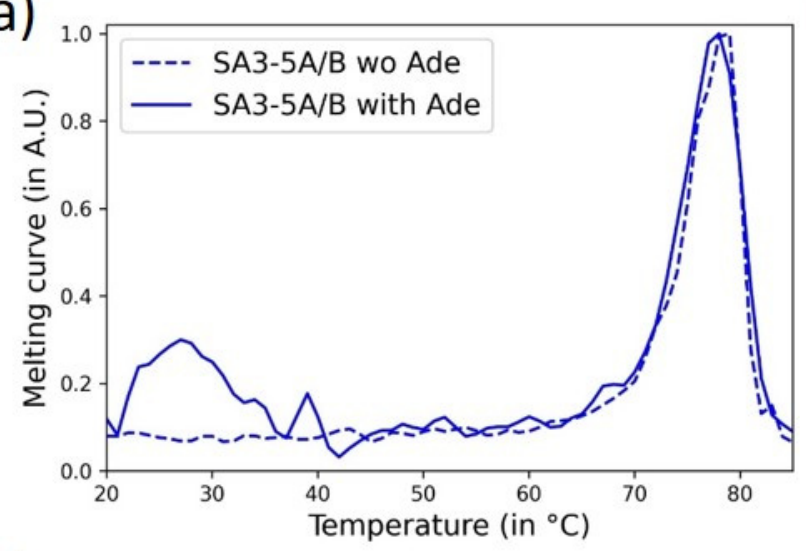

c)

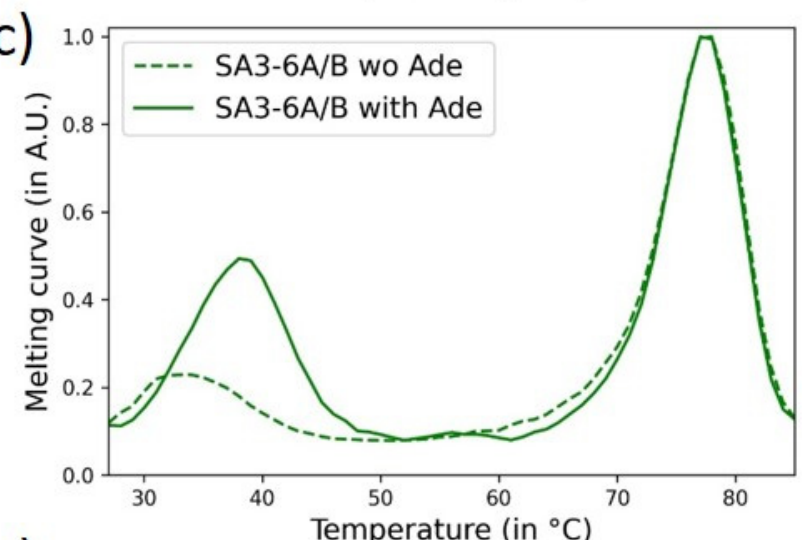

e)

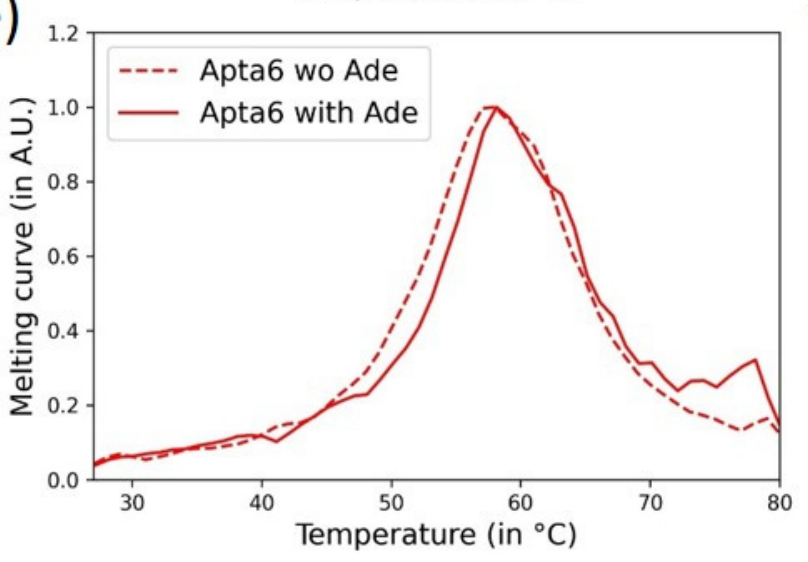

b)
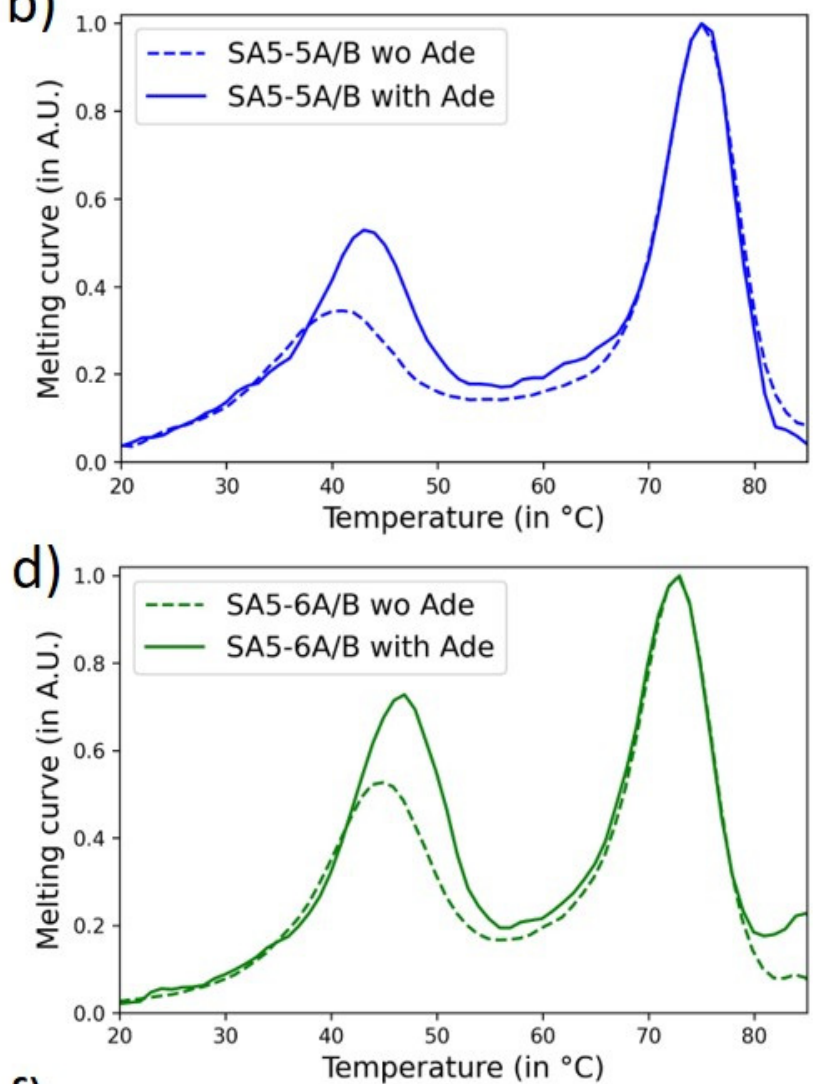

f)

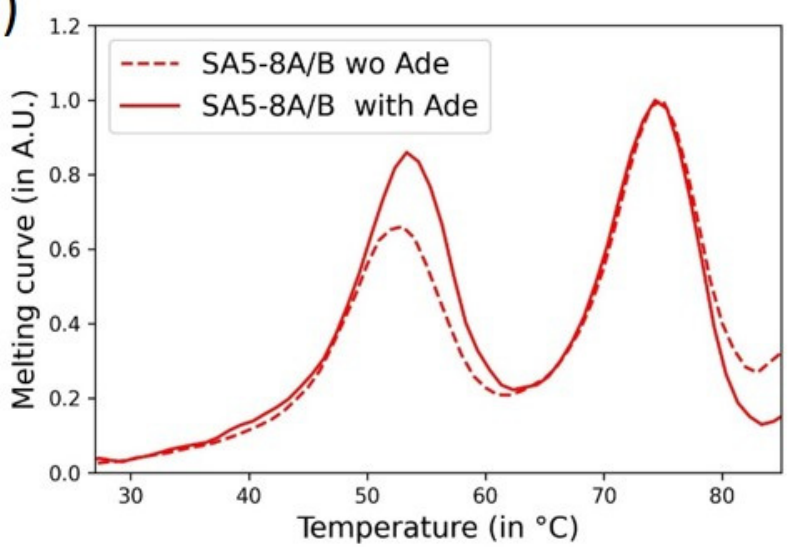

Figure 1. Melting curves (normalized first derivative of the UV absorbance) for the different sequence designs (a) SA3-5A/B, (b) SA5-5A/B, (c) SA3-6A/B, (d) SA5-6A/B, (e) Apta6, and (f) SA5-8A/B) with $100 \mu \mathrm{M}$ adenosine (full line) and without (dotted line) in the solution. Peaks relate to aptamer bridges and aptachain formation (first peak) and dimers formation through Zip hybridization (second peak), respectively. The second peak maximum has been set to one for normalization. The concentrations of the DNA strands were set to $0.9 \mu \mathrm{M}$ in all experiments. The full aptamer Apta6 only showed one peak corresponding to the formation of the aptamer bridge or hairpin configuration in this case and its maximum value was normalized to one.

In general, the first melting peaks were affected by the binding strength of the aptamer bridge. The higher the number of hybridization base pairs (hbps), the larger 
the corresponding melting temperature: $\mathrm{T}_{\mathrm{m}}=33.3+/-1{ }^{\circ} \mathrm{C}$ for SA3-6A/B (9 hbps), $\mathrm{T}_{\mathrm{m}}=40.5+/-1{ }^{\circ} \mathrm{C}$ for SA5-5A/B (10 hbps), $\mathrm{T}_{\mathrm{m}}=44.5+/-1{ }^{\circ} \mathrm{C}$ for SA5-6A/B (11 hbps), and $\mathrm{T}_{\mathrm{m}}=51.5+/-1^{\circ} \mathrm{C}$ for SA5-8A/B (13 hbps). As a comparison, the melting curve of the full aptamer only showed one melting peak regardless of the presence of adenosine. The melting temperature $\mathrm{T}_{\mathrm{m}}=57.5+/-1{ }^{\circ} \mathrm{C}$ for the aptamer Apta6 is higher than for the binding of split-aptamers (even though the number of hpbs is higher for the dimer SA5-8A/B). This may be explained by the fact that in the case of the full aptamer, the melting corresponds to the folding/unfolding of a single oligonucleotide hairpin. For split-aptamers, the hybridization of two different oligonucleotide sequences implied an additive entropic effect explaining the lower melting temperature. For further studies, it would be interesting to analyze the effect of the loop size in the full aptamer. Most of the studies considered the original sequence with only a single thymine in the loop. However, larger loops may lead to lower hairpin melting temperatures and the increased flexibility of the loop could have an impact on the affinity of the aptamer. When comparing with the full aptamer reference, another difference concerns the shift in melting temperature when introducing adenosine. This shift $\Delta \mathrm{T}_{\mathrm{m}}$ is small (less than $1^{\circ} \mathrm{C}$ ) for the full aptamer compared to the aptachain structures $\left(\Delta \mathrm{T}_{\mathrm{m}}=5.5^{\circ} \mathrm{C}\right.$ for SA3-6A/B,$\Delta \mathrm{T}_{\mathrm{m}}=2.5^{\circ} \mathrm{C}$ for SA5-5A/B, and SA5-6A/B, $\Delta \mathrm{T}_{\mathrm{m}}=2{ }^{\circ} \mathrm{C}$ for SA5-8A/B, while not measurable for SA3-5A/B due to the absence of melting peak without adenosine). Moreover, in the case of the aptachain structure, a reliable increase in the intensity of the first peak with the presence of $100 \mu \mathrm{M}$ adenosine was observed after the normalization calibration by the second peak. In the case of the full aptamer, the direct comparison between the intensities of the single peak with and without adenosine may be hampered by slight changes in solution content and aptamer concentration due to the lack of internal calibration.

Interestingly, the presence of adenosine has an effect on both the maximum height and the melting temperature of the first peak. In all cases, the increase in the maximum height and melting temperature was observed to be more important for the lower aptamer bridge stability. It was evident for the lowest stability (SA3-5A/B) since the first peak was not observed (even for temperature as low as $5{ }^{\circ} \mathrm{C}$ ) in the absence of adenosine. Furthermore, the relative increase in both maximum height and melting temperature seemed to decrease with the DNA architecture increasing stability. We may explain this observation by the fact that the stability brought by the adenosine binding to the pocket is independent of the dimer designs (since the pocket is not modified by the various designs) while, on the contrary, the hybridization stability increased with the number of hbps present (thus reducing the relative effect of the presence of adenosine).

Based on those observations, the optimal design seemed to be SA3-6A/B since it presented the highest shift in melting temperature and maximum height variation while introducing adenosine in the solution. The design SA3-5A/B could also be of interest since the first peak is clearly absent without adenosine but appears in its presence. However, the first melting peak is observed at low temperatures, which require working with a larger temperature range from $5{ }^{\circ} \mathrm{C}$ to $90{ }^{\circ} \mathrm{C}$, rendering the experiment more time-consuming and noisier. The noise observed at low temperature may come from two different effects: the salt precipitation of the solvent inside the cuvette and the condensation outside the cuvette. Thus, the following set of experiments was focused on the SA3-6A/B design.

\subsection{Impact of Adenosine Concentration on Aptachain Formation}

In this section, we focused on the SA3-6A/B dimer design and analyzed the evolution of the first melting peak as a function of adenosine concentration in order to understand the aptachain formation thermodynamics and to determine how it may be used for adenosine quantification. The first melting peak was strongly affected by the increasing concentration of adenosine (for $\mathrm{c}=0,5,10,20,50$, and $100 \mu \mathrm{M}$ see Figure 2) while the second peak could serve as a normalization (no apparent change of the melting temperature). Furthermore, guanosine was used as a negative control to assess the selectivity. The melting curve for 
$100 \mu \mathrm{M}$ guanosine lies between the melting curves without and with $5 \mu \mathrm{M}$ of adenosine confirming the selectivity of the adenosine (split-)aptamer.

As seen in Figure 2, not only the shift in the melting temperature of the first peak, but also its height may be used to determine the presence of adenosine in the solution. The heights of the first peak are presented as a function of adenosine concentration in Figure 3 Left. A continuous increase of the first peak is observed with the increase in adenosine concentration $\mathrm{c}$, leading to saturation at high concentration. We may relate such an increase to the amount of aptamer bridges induced by adenosine. By fitting with a Langmuir model $\mathrm{P}=\mathrm{P} 0+\Delta \mathrm{Pmax} c /\left(\mathrm{K}_{\mathrm{D}}+\mathrm{c}\right)$ with the peak height $\mathrm{P}$ and the fitting parameters: $\mathrm{P} 0$, the height without adenosine, $\Delta \mathrm{Pmax}$, the maximal shift in height value, and $\mathrm{K}_{\mathrm{D}}$ the dissociation constant, we determined $\mathrm{K}_{\mathrm{D}}=19+/-2 \mu \mathrm{M}$. As expected, this value is slightly higher than the full aptamer dissociation constant $\left(K_{D}=7 \mu \mathrm{M}\right)$ due to the splitting of the aptamer into two strands [14,27]. Still, the difference is minimal illustrating the low impact of the splitting on the binding recognition. The signal to noise ratio for the concentration $5 \mu \mathrm{M}$ of adenosine is above 3 (with a noise in the peak height estimated around 0.005). However, the signal observed with $100 \mu \mathrm{M}$ of guanosine (blue curve on Figure 2) is close to the signal obtained for $5 \mu \mathrm{M}$ of adenosine. Thus, we cannot expect to selectively detect adenosine below $5 \mu \mathrm{M}$. On Figure $3 \mathrm{Left}$, the first peak maximum is close to saturation for adenosine concentration of $100 \mu \mathrm{M}$, thus leading to a dynamic range between 5 to $100 \mu \mathrm{M}$. The limit of detection ( $\mathrm{LOD}=5 \mu \mathrm{M}$ ) of our biosensor is comparable with similar homogenous phase detection for aptamer-based small molecule detection without amplification $[21,23,54,56-58]$.

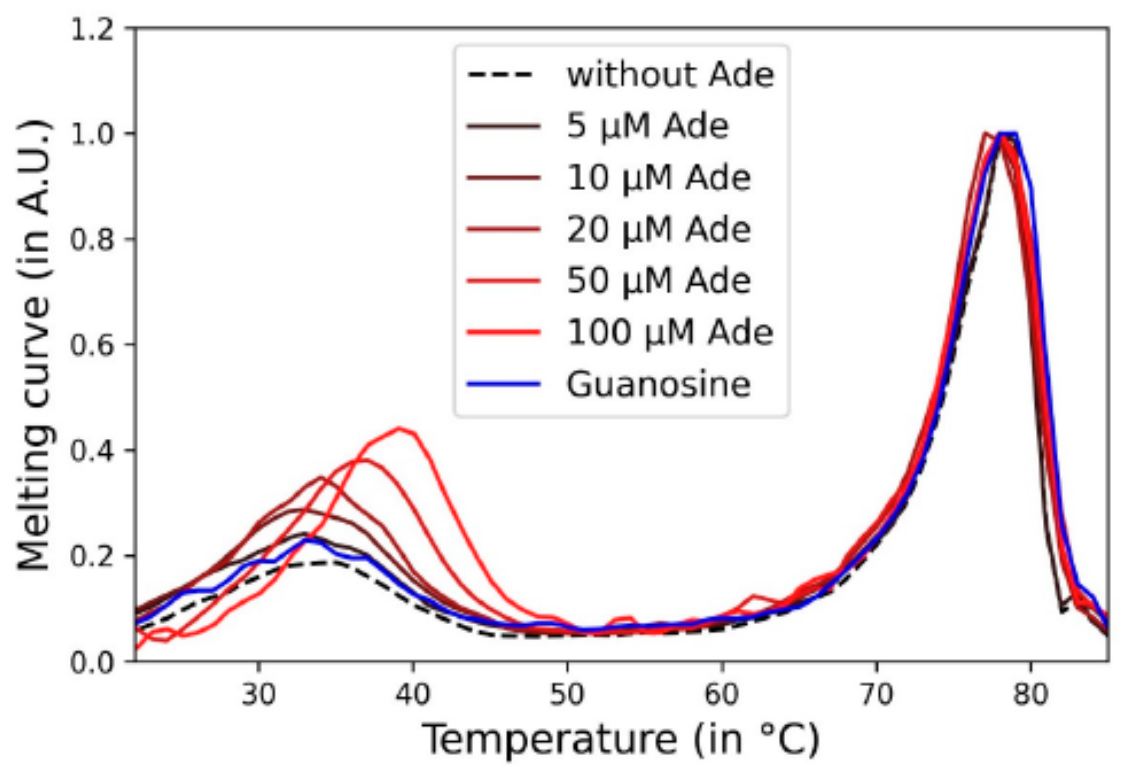

Figure 2. Melting curves for the dimer design SA3-6A/B with an increasing concentration of adenosine $(c=0,5,10,20,50$, and $100 \mu \mathrm{M})$ and for $100 \mu \mathrm{M}$ of guanosine to assess selectivity. Oligonucleotide sequences concentrations were set at $0.9 \mu \mathrm{M}$.

Now, let us focus on the temperature shift (Figure 3 Right). When the concentration of adenosine was below $20 \mu \mathrm{M}$, the melting peak showed no clear temperature shift while the height of the peak was clearly increasing. Indeed, the melting temperatures observed up to $20 \mu \mathrm{M}$ of adenosine lie within the error bar of the one observed without adenosine (blue band in Figure 3 Right). However, the melting temperature shifted by $+3^{\circ} \mathrm{C}$ and nearly $+6^{\circ} \mathrm{C}$, respectively for $50 \mu \mathrm{M}$ and $100 \mu \mathrm{M}$ of adenosine. In the meantime, the maximum peak height increased linearly from 0.18 to 0.35 when the concentration of adenosine increased from 0 to $20 \mu \mathrm{M}$ and finally reached 0.44 with the presence of $100 \mu \mathrm{M}$ adenosine in the solution. Thus, the increase of the peak height was more pronounced at adenosine concentrations lower than $20 \mu \mathrm{M}$. In conclusion, the shift in peak height is clearly more 
relevant to detect and quantify the adenosine concentration at low adenosine concentration than the shift in melting temperature. This indicates once again the importance of a normalization procedure to consistently and precisely measure the peak height.
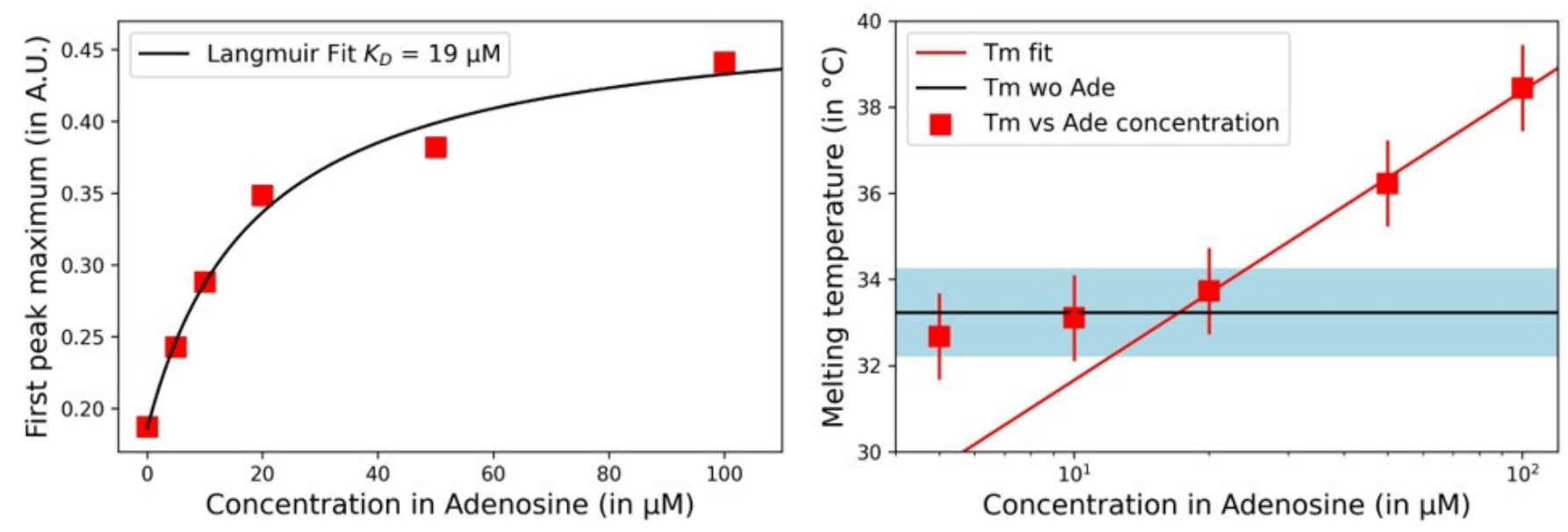

Figure 3. (Left): First peak height maximum for SA3-6A/B dimer and various adenosine concentrations $(c=0,5,10$, 20, 50, and $100 \mu \mathrm{M})$. The Langmuir fit leads to $\mathrm{K}_{\mathrm{D}}=19 \mu \mathrm{M}$. Error bars are smaller than the square symbols. (Right): Melting temperature of the aptachains as a function of adenosine concentration. The horizontal band represents the melting temperature without adenosine with its error bar. The red line is a logarithmic fit of the last three points. The oligonucleotides concentration in all the samples was set to $0.9 \mu \mathrm{M}$.

Interestingly, the melting temperature effect observed as a function of the adenosine concentration qualitatively follows the behavior illustrated in Scheme 2. We may expect that two competing melting/binding temperature-dependent events are involved. First, the aptamer bridges formation occurs at a melting temperature $\mathrm{T}_{\mathrm{m}}$ (bridge) independent of the concentration of adenosine. Secondly, the binding of adenosine within the aptamer pocket is obviously influenced by the adenosine concentration c(Ade), but is also temperature dependent through the dissociation constant $\mathrm{K}_{\mathrm{D}}(\mathrm{T})$. In fact, we expect that half of the bridges are bound by adenosine when, $K_{D}(T)=c$ (Ade) defining an adenosine concentration-dependent melting temperature $\mathrm{T}_{\mathrm{m}}$ (Ade) which is logarithmically increasing with the adenosine concentration (illustrated in red in Scheme 2). Indeed, at low adenosine concentration, the melting temperature $\mathrm{T}_{\mathrm{m}}$ (bridge) of the aptamer bridge is higher than $\mathrm{T}_{\mathrm{m}}$ (Ade) at which the adenosine would bind to the aptamer pocket. Thus, the observed melting temperature $\mathrm{T}_{\mathrm{m}}$ (bridge) is constant while the binding of adenosine below this temperature may explain the increase in peak height. With higher concentration of adenosine, the increasing melting temperature $\mathrm{T}_{\mathrm{m}}$ (Ade) is observed due to the stabilization of the aptamer bridges by the binding of adenosine. We effectively observed a linear increase of the melting temperature as a function of the logarithm of the adenosine concentration (Figure 3 Right). The overlap between the two different temperature regimes occurs at $\mathrm{c}($ Ade $)=\mathrm{K}_{\mathrm{D}}(\mathrm{Tm}($ bridge $))=20 \mu \mathrm{M}$, which is consistent with the $\mathrm{K}_{\mathrm{D}}$ value extracted from the Langmuir fit (Figure 3 Left).

\subsection{Influence of the Salt Concentration}

The benefit of the internal reference in the detection method lies in the reduction of the influence of the buffer composition. In order to prove this point, experiments were carried out comparing the UV-Vis spectroscopy data obtained with different buffers. To begin with, we used a buffer with the same preparation protocol but not in the same batch and not on the same day. In the first set of tests, the two peaks were at $33{ }^{\circ} \mathrm{C}\left(\mathrm{T}_{\mathrm{m} 1}\right)$ and $77{ }^{\circ} \mathrm{C}\left(\mathrm{T}_{\mathrm{m} 2}\right)$ without adenosine. The first peak shifted to $38^{\circ} \mathrm{C}$ with $100 \mu \mathrm{M}$ of adenosine in the solution while the second peak remained the same. The value of all peaks had a $1^{\circ} \mathrm{C}$ difference compared to the second set of tests. The peaks without adenosine were at $34^{\circ} \mathrm{C}\left(\mathrm{T}_{\mathrm{m} 1}\right)$ and $78^{\circ} \mathrm{C}\left(\mathrm{T}_{\mathrm{m} 2}\right)$, and the first peak shifted to $39^{\circ} \mathrm{C}$ with $100 \mu \mathrm{M}$ of adenosine in the solution. 
Slight differences in the buffer resulted in different melting temperatures measured, but the difference between the two melting peaks remained the same. The results supported our claim that the internal reference is an important element enabling the detection of adenosine regardless of the minor difference produced in the preparation of the buffer.

Furthermore, we prepared buffers with different salt concentrations to see how it affected the melting profiles. The $10 \times$ buffer was diluted into three different concentrations: $0.5 \times$ buffer, $1 \times$ buffer, and $1.5 \times$ buffer, respectively. Different samples with different concentrations of adenosine $(0$ and $100 \mu \mathrm{M})$ and buffer concentrations were prepared. In order to observe the interest in the normalization, melting curves were represented in Figure 4 with the dimer peak normalized to one as a function of the difference temperature $\Delta \mathrm{T}=\mathrm{T}_{\mathrm{m}}$ (dimer) $-\mathrm{T}$. The value of the peak corresponding to the dimer formation was thus set at $\Delta \mathrm{T}=0{ }^{\circ} \mathrm{C}$ with $100 \mu \mathrm{M}$ of adenosine or without adenosine. We observed that independently of the buffer concentration, with the presence of $100 \mu \mathrm{M}$ of adenosine in the solution, the difference between the two melting peaks was kept constant at $39^{\circ} \mathrm{C}$. The height of the peaks was also similar, although a slight difference was observed for the low salt concentration $(0.5 \times)$. The exact values of these melting peaks were not the same before normalization, which suggested that the melting temperatures were affected by the salt concentration in the buffer as commonly observed for oligonucleotide hybridization assays [59-61]. Thus, the detection was still reliable thanks to the internal reference. We further noticed that the difference between the two melting peaks without adenosine was increased to $46^{\circ} \mathrm{C}$ for $0.5 \times$ buffer compared to $44^{\circ} \mathrm{C}$ for $1 \times$ buffer and $1.5 \times$ buffer. The larger difference between the two peaks suggested that the binding strength was weaker in the case of $0.5 \times$ buffer without adenosine. A possible reason is that the lack of salt led to unsaturated formation of aptamer bridges increasing the effect on its melting temperature (right peaks in Figure 4). On the contrary, the other two buffers contained enough salt to saturate the formation of aptamer bridges. Thus, the internal reference may rule out the influence caused by differences in the buffer concentration, but the salt concentration needs to be high enough to saturate the formation of aptamer bridges.

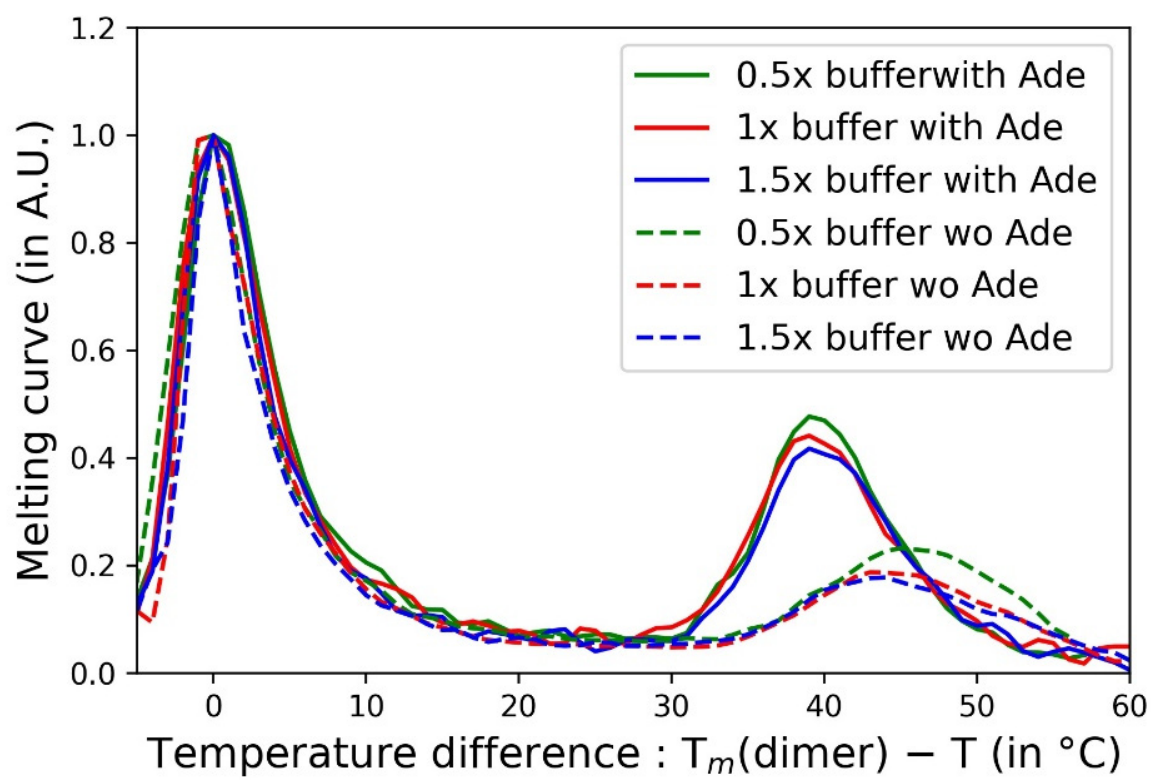

Figure 4. Melting curves normalized by the height of the dimer peak as a function of the temperature difference, $\mathrm{T}_{\mathrm{m}}$ (dimer) $-\mathrm{T}$, for three buffer conditions $(0.5 \times$ green, $1 \times$ blue and $1.5 \times$ red $)$ with $100 \mu \mathrm{M}$ adenosine (full line) and without adenosine (dashed line). Note that due to the temperature difference expressed as $\mathrm{T}_{\mathrm{m}}$ (dimer) - $\mathrm{T}$, the aptamer bridge melting peaks are on the right side of the figure while the reference dimer melting peaks are centered at $0{ }^{\circ} \mathrm{C}$. 


\subsection{Influence of Oligonucleotide Concentrations}

The concentration of the oligonucleotide strands was another parameter affecting the melting curves. Figure 5 Left presents the melting curves before calibration. The two melting peaks exhibited a very small shift with the change of strand concentrations. On the other hand, the heights of both peaks strongly increased with the oligonucleotide concentrations. We observed increasing noise for samples with lower oligonucleotide concentrations. Their melting curves were smoothed with the Savitzky-Golay method to reduce the noise [62]. In contrast, for higher concentrations, there is a risk of saturating the signal. Thus, as mentioned in the protocol, the oligonucleotide concentration was preferable at $0.9 \mu \mathrm{M}$ in order to have the best resolution in the melting curve of the aptachain structures. By comparing the melting profile after the normalization of the second melting peak (Figure 5 Right), we noticed that the heights of the first peak were similar to each other. Thus, the normalization proposed by the internal control may correct the height variations of the first melting peak observed due to the variation in concentration of the oligonucleotides.
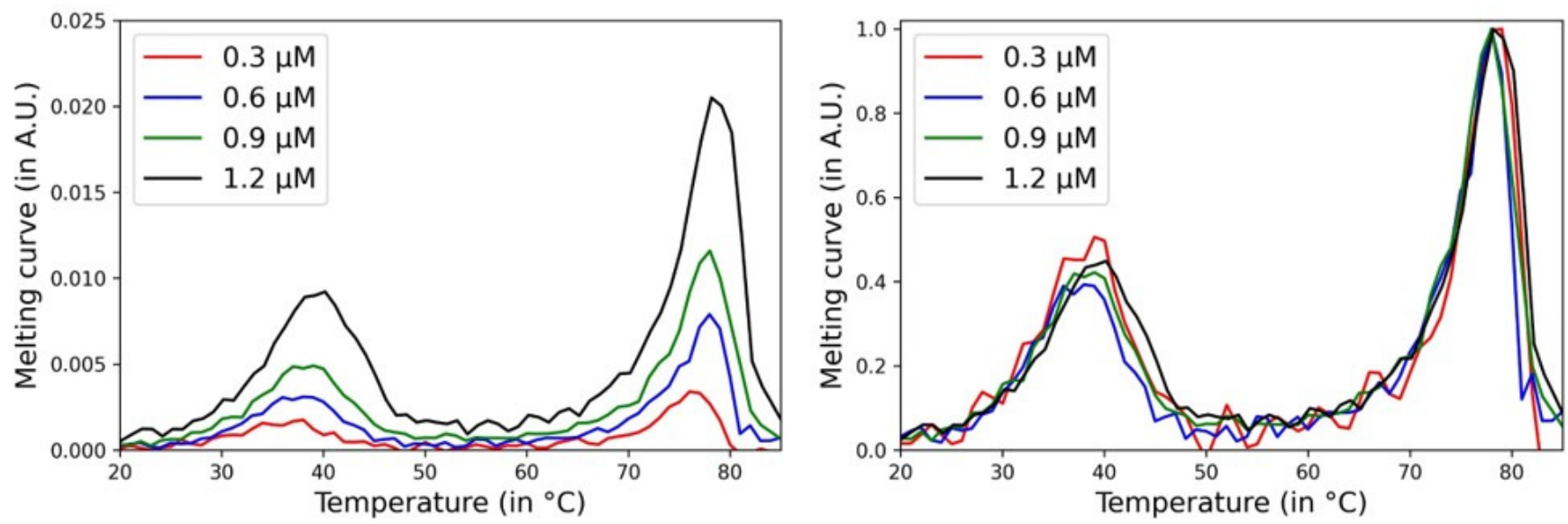

Figure 5. Melting curves with $100 \mu \mathrm{M}$ adenosine in the solution for various oligonucleotide concentrations $(0.3,0.6,0.9$, and $1.2 \mu \mathrm{M})$ without (Left) and with (Right) normalization.

\section{Conclusions}

In this study, we analyzed the formation of aptachains composed of dimers with split-aptamers towards adenosine as dangling ends. Two different melting temperatures leading to the formation of the aptachains at low temperatures were determined from UV absorbance at $260 \mathrm{~nm}$. The higher melting temperature was related to the dimer formation while the lower melting temperature was representative of the aptamer bridges. Due to the target recognition and further stabilization of the aptamer bridges, the lower melting peak was shown to be target concentration-dependent. Various aptamer sequences were considered to select the most sensitive for the detection of the aptamer target adenosine. Thus, we developed a homogenous phase biosensor for the label-free detection of small targets based on the UV melting curve analysis of aptachains. We obtained a limit of detection of $5 \mu \mathrm{M}$ which is similar to previous studies without amplification.

While in this study, we considered UV absorbance at $260 \mathrm{~nm}$ to reveal the aptachain formation and to characterize the melting curves, other homogeneous techniques could be used based on fluorescence of intercalating dies [63], fluorescence polarization or anisotropy [56,64-67] to mention a few. Heterogeneous assays may also be considered to allow for simple multiplexing of target detection. For example, melting curve analysis of multiple oligonucleotide probes in parallel was demonstrated with the use of surface plasmon resonance imaging $[28,60,68-70]$. Recently, the formation of aptachains on surfaces was demonstrated by such a transduction technique [41]. It is also interesting to notice that cooperativity effects may sharpen the melting in case of comb-like DNA polymers or 
nanoparticles [71,72]. It would be interesting to understand if such structures could have an effect on the detection limit of the biosensors.

Supplementary Materials: The following are available online at https:/ /www.mdpi.com/article/10 .3390/bios11040112/s1, Figure S1: Temperature scans; Figure S2: Gel electrophoresis.

Author Contributions: Conceptualization, D.G., Y.R., E.P., and A.B.; formal analysis, C.L., C.S.-P., and C.R.; funding acquisition, E.P. and A.B.; investigation, C.L., C.S.-P., and C.R.; supervision, D.G., E.P., and A.B.; validation, C.L., C.S.-P., and C.R.; writing-original draft, C.L. and A.B.; writingreview and editing, C.L., C.S.-P., D.G., Y.R., C.R., E.P., and A.B. All authors have read and agreed to the published version of the manuscript.

Funding: This work was supported by Labex ARCANE and CBH-EUR-GS (ANR-17-EURE-0003).

Data Availability Statement: Data are accessible upon request to the authors.

Conflicts of Interest: The authors declare no conflict of interest.

\section{References}

1. Schwarzenbach, R.P.; Escher, B.I.; Fenner, K.; Hofstetter, T.B.; Johnson, C.A.; von Gunten, U.; Wehrli, B. The Challenge of Micropollutants in Aquatic Systems. Science 2006, 313, 1072-1077. [CrossRef] [PubMed]

2. Benotti, M.J.; Trenholm, R.A.; Vanderford, B.J.; Holady, J.C.; Stanford, B.D.; Snyder, S.A. Pharmaceuticals and Endocrine Disrupting Compounds in U.S. Drinking Water. Environ. Sci. Technol. 2009, 43, 597-603. [CrossRef] [PubMed]

3. Qi, X.; Yan, X.; Zhao, Y.; Li, L.; Wang, S. Highly Sensitive and Specific Detection of Small Molecules Using Advanced Aptasensors Based on Split Aptamers: A Review. Trac. Trends Anal. Chem. 2020, 133, 116069. [CrossRef]

4. Prante, M.; Segal, E.; Scheper, T.; Bahnemann, J.; Walter, J. Aptasensors for Point-of-Care Detection of Small Molecules. Biosensors 2020, 10, 108. [CrossRef]

5. Ziółkowski, R.; Jarczewska, M.; Górski, Ł.; Malinowska, E. From Small Molecules toward Whole Cells Detection: Application of Electrochemical Aptasensors in Modern Medical Diagnostics. Sensors 2021, 21, 724. [CrossRef]

6. Tuerk, C.; Gold, L. Systematic Evolution of Ligands by Exponential Enrichment: RNA Ligands to Bacteriophage T4 DNA Polymerase. Science 1990, 249, 505-510. [CrossRef]

7. Ellington, A.D.; Szostak, J.W. In Vitro Selection of RNA Molecules That Bind Specific Ligands. Nature 1990, 346, 818-822. [CrossRef]

8. Song, S.; Wang, L.; Li, J.; Fan, C.; Zhao, J. Aptamer-Based Biosensors. Trac. Trends Anal. Chem. 2008, 27, 108-117. [CrossRef]

9. Cho, E.J.; Lee, J.-W.; Ellington, A.D. Applications of Aptamers as Sensors. Annu. Rev. Anal. Chem. 2009, 2, 241-264. [CrossRef]

10. Chen, A.; Yang, S. Replacing Antibodies with Aptamers in Lateral Flow Immunoassay. Biosens. Bioelectron. 2015, 71, 230-242. [CrossRef]

11. Toh, S.Y.; Citartan, M.; Gopinath, S.C.B.; Tang, T.-H. Aptamers as a Replacement for Antibodies in Enzyme-Linked Immunosorbent Assay. Biosens. Bioelectron. 2015, 64, 392-403. [CrossRef]

12. Seok Kim, Y.; Ahmad Raston, N.H.; Bock Gu, M. Aptamer-Based Nanobiosensors. Biosens. Bioelectron. 2016, 76, 2-19. [CrossRef]

13. Dhiman, A.; Kalra, P.; Bansal, V.; Bruno, J.G.; Sharma, T.K. Aptamer-Based Point-of-Care Diagnostic Platforms. Sens. Actuators B Chem. 2017, 246, 535-553. [CrossRef]

14. Huizenga, D.E.; Szostak, J.W. A DNA Aptamer That Binds Adenosine and ATP. Biochemistry 1995, 34, 656-665. [CrossRef]

15. Stojanovic, M.N.; de Prada, P.; Landry, D.W. Fluorescent Sensors Based on Aptamer Self-Assembly. J. Am. Chem. Soc. 2000, 122, 11547-11548. [CrossRef]

16. Baker, B.R.; Lai, R.Y.; Wood, M.S.; Doctor, E.H.; Heeger, A.J.; Plaxco, K.W. An Electronic, Aptamer-Based Small-Molecule Sensor for the Rapid, Label-Free Detection of Cocaine in Adulterated Samples and Biological Fluids. J. Am. Chem. Soc. 2006, 128, 3138-3139. [CrossRef]

17. McKeague, M.; DeRosa, M.C. Challenges and Opportunities for Small Molecule Aptamer Development. Available online: https:/ / www.hindawi.com/journals/jna/2012/748913/ (accessed on 3 February 2021).

18. Alkhamis, O.; Canoura, J.; Yu, H.; Liu, Y.; Xiao, Y. Innovative Engineering and Sensing Strategies for Aptamer-Based SmallMolecule Detection. Trac. Trends Anal. Chem. 2019, 121, 115699. [CrossRef]

19. McKeague, M.; De Girolamo, A.; Valenzano, S.; Pascale, M.; Ruscito, A.; Velu, R.; Frost, N.R.; Hill, K.; Smith, M.; McConnell, E.M.; et al. Comprehensive Analytical Comparison of Strategies Used for Small Molecule Aptamer Evaluation. Anal. Chem. 2015, 87, 8608-8612. [CrossRef]

20. Liu, J.; Lu, Y. Adenosine-Dependent Assembly of Aptazyme-Functionalized Gold Nanoparticles and Its Application as a Colorimetric Biosensor. Anal. Chem. 2004, 76, 1627-1632. [CrossRef]

21. Liu, J.; Lu, Y. Fast Colorimetric Sensing of Adenosine and Cocaine Based on a General Sensor Design Involving Aptamers and Nanoparticles. Angew. Chem. 2006, 118, 96-100. [CrossRef]

22. Chen, S.-J.; Huang, Y.-F.; Huang, C.-C.; Lee, K.-H.; Lin, Z.-H.; Chang, H.-T. Colorimetric Determination of Urinary Adenosine Using Aptamer-Modified Gold Nanoparticles. Biosens. Bioelectron. 2008, 23, 1749-1753. [CrossRef] [PubMed] 
23. Li, F.; Zhang, J.; Cao, X.; Wang, L.; Li, D.; Song, S.; Ye, B.; Fan, C. Adenosine Detection by Using Gold Nanoparticles and Designed Aptamer Sequences. Analyst 2009, 134, 1355-1360. [CrossRef] [PubMed]

24. Bai, Y.; Feng, F.; Zhao, L.; Chen, Z.; Wang, H.; Duan, Y. A Turn-on Fluorescent Aptasensor for Adenosine Detection Based on Split Aptamers and Graphene Oxide. Analyst 2014, 139, 1843. [CrossRef] [PubMed]

25. Wang, Y.; Feng, J.; Tan, Z.; Wang, H. Electrochemical Impedance Spectroscopy Aptasensor for Ultrasensitive Detection of Adenosine with Dual Backfillers. Biosens. Bioelectron. 2014, 60, 218-223. [CrossRef]

26. Li, Y.; Liu, J. Aptamer-Based Strategies for Recognizing Adenine, Adenosine, ATP and Related Compounds. Analyst 2020, 145, 6753-6768. [CrossRef]

27. Melaine, F.; Roupioz, Y.; Buhot, A. Gold Nanoparticles Surface Plasmon Resonance Enhanced Signal for the Detection of Small Molecules on Split-Aptamer Microarrays (Small Molecules Detection from Split-Aptamers). Microarrays 2015, 4, 41-52. [CrossRef]

28. Melaine, F.; Coilhac, C.; Roupioz, Y.; Buhot, A. A Nanoparticle-Based Thermo-Dynamic Aptasensor for Small Molecule Detection. Nanoscale 2016, 8, 16947-16954. [CrossRef]

29. Melaine, F.; Roupioz, Y.; Buhot, A. Small Molecule SPR Imaging Detection from Split Aptamer Microarrays. Procedia Technol. 2017, 27, 6-7. [CrossRef]

30. Lopez, A.; Liu, J. Nanomaterial and Aptamer-Based Sensing: Target Binding versus Target Adsorption Illustrated by the Detection of Adenosine and ATP on Metal Oxides and Graphene Oxide. Anal. Chem. 2021, 93, 3018-3025. [CrossRef]

31. Holden, M.J.; Haynes, R.J.; Rabb, S.A.; Satija, N.; Yang, K.; Blasic, J.R. Factors Affecting Quantification of Total DNA by UV Spectroscopy and PicoGreen Fluorescence. J. Agric. Food Chem. 2009, 57, 7221-7226. [CrossRef]

32. Fuchs, J.; Dell'Atti, D.; Buhot, A.; Calemczuk, R.; Mascini, M.; Livache, T. Effects of Formamide on the Thermal Stability of DNA Duplexes on Biochips. Anal. Biochem. 2010, 397, 132-134. [CrossRef]

33. Bhat, S.; Curach, N.; Mostyn, T.; Bains, G.S.; Griffiths, K.R.; Emslie, K.R. Comparison of Methods for Accurate Quantification of DNA Mass Concentration with Traceability to the International System of Units. Anal. Chem. 2010, 82, 7185-7192. [CrossRef]

34. Bi, S.; Yue, S.; Zhang, S. Hybridization Chain Reaction: A Versatile Molecular Tool for Biosensing, Bioimaging, and Biomedicine. Chem. Soc. Rev. 2017, 46, 4281-4298. [CrossRef]

35. Choi, H.M.T.; Beck, V.A.; Pierce, N.A. Next-Generation in Situ Hybridization Chain Reaction: Higher Gain, Lower Cost, Greater Durability. ACS Nano 2014, 8, 4284-4294. [CrossRef]

36. Dirks, R.M.; Pierce, N.A. Triggered Amplification by Hybridization Chain Reaction. Proc. Natl. Acad. Sci. USA 2004, 101, 15275-15278. [CrossRef]

37. Evanko, D. Hybridization Chain Reaction. Nat. Methods 2004, 1, 186. [CrossRef]

38. Figg, C.A.; Winegar, P.H.; Hayes, O.G.; Mirkin, C.A. Controlling the DNA Hybridization Chain Reaction. J. Am. Chem. Soc. 2020, 142, 8596-8601. [CrossRef]

39. Zhang, C.; Chen, J.; Sun, R.; Huang, Z.; Luo, Z.; Zhou, C.; Wu, M.; Duan, Y.; Li, Y. The Recent Development of Hybridization Chain Reaction Strategies in Biosensors. ACS Sens. 2020, 5, 2977-3000. [CrossRef]

40. Zeng, Z.; Zhou, R.; Sun, R.; Zhang, X.; Cheng, Z.; Chen, C.; Zhu, Q. Nonlinear Hybridization Chain Reaction-Based Functional DNA Nanostructure Assembly for Biosensing, Bioimaging Applications. Biosens. Bioelectron. 2021, 173, 112814. [CrossRef]

41. Lu, C.; Saint-Pierre, C.; Gasparutto, D.; Roupioz, Y.; Peyrin, E.; Buhot, A. Linear Chain Formation of Split-Aptamer Dimers on Surfaces Triggered by Adenosine. Langmuir 2017, 33, 12785-12792. [CrossRef]

42. Wang, J.; Cheng, W.; Meng, F.; Yang, M.; Pan, Y.; Miao, P. Hand-in-Hand RNA Nanowire-Based Aptasensor for the Detection of Theophylline. Biosens. Bioelectron. 2018, 101, 153-158. [CrossRef]

43. Azéma, L.; Bonnet-Salomon, S.; Endo, M.; Takeuchi, Y.; Durand, G.; Emura, T.; Hidaka, K.; Dausse, E.; Sugiyama, H.; Toulmé, J.-J. Triggering Nucleic Acid Nanostructure Assembly by Conditional Kissing Interactions. Nucleic Acids Res. 2018, 46, 1052-1058. [CrossRef]

44. Neves, M.A.D.; Slavkovic, S.; Reinstein, O.; Shoara, A.A.; Johnson, P.E. A Proof of Concept Application of Aptachain: LigandInduced Self-Assembly of a DNA Aptamer. RSC Adv. 2019, 9, 1690-1695. [CrossRef]

45. Taton, T.A.; Mucic, R.C.; Mirkin, C.A.; Letsinger, R.L. The DNA-Mediated Formation of Supramolecular Mono- and Multilayered Nanoparticle Structures. J. Am. Chem. Soc. 2000, 122, 6305-6306. [CrossRef]

46. Storhoff, J.J.; Lazarides, A.A.; Mucic, R.C.; Mirkin, C.A.; Letsinger, R.L.; Schatz, G.C. What Controls the Optical Properties of DNA-Linked Gold Nanoparticle Assemblies? J. Am. Chem. Soc. 2000, 122, 4640-4650. [CrossRef]

47. Xia, F.; Zuo, X.; Yang, R.; Xiao, Y.; Kang, D.; Vallée-Bélisle, A.; Gong, X.; Yuen, J.D.; Hsu, B.B.Y.; Heeger, A.J.; et al. Colorimetric Detection of DNA, Small Molecules, Proteins, and Ions Using Unmodified Gold Nanoparticles and Conjugated Polyelectrolytes. Proc. Natl. Acad. Sci. USA 2010, 107, 10837-10841. [CrossRef]

48. Tomaszewska, E.; Soliwoda, K.; Kadziola, K.; Tkacz-Szczesna, B.; Celichowski, G.; Cichomski, M.; Szmaja, W.; Grobelny, J. Detection Limits of DLS and UV-Vis Spectroscopy in Characterization of Polydisperse Nanoparticles Colloids. J. Nanomater. 2013, 2013, 60. [CrossRef]

49. Bishop, G.R.; Ren, J.; Polander, B.C.; Jeanfreau, B.D.; Trent, J.O.; Chaires, J.B. Energetic Basis of Molecular Recognition in a DNA Aptamer. Biophys. Chem. 2007, 126, 165-175. [CrossRef]

50. Liu, J.; Lu, Y. Non-Base Pairing DNA Provides a New Dimension for Controlling Aptamer-Linked Nanoparticles and Sensors. J. Am. Chem. Soc. 2007, 129, 8634-8643. [CrossRef] 
51. Song, K.-M.; Cho, M.; Jo, H.; Min, K.; Jeon, S.H.; Kim, T.; Han, M.S.; Ku, J.K.; Ban, C. Gold Nanoparticle-Based Colorimetric Detection of Kanamycin Using a DNA Aptamer. Anal. Biochem. 2011, 415, 175-181. [CrossRef]

52. Patel, M.; Dutta, A.; Huang, H. A Selective Adenosine Sensor Derived from a Triplex DNA Aptamer. Anal. Bioanal. Chem. 2011, 400, 3035-3040. [CrossRef] [PubMed]

53. Slavkovic, S.; Zhu, Y.; Churcher, Z.R.; Shoara, A.A.; Johnson, A.E.; Johnson, P.E. Thermodynamic Analysis of Cooperative Ligand Binding by the ATP-Binding DNA Aptamer Indicates a Population-Shift Binding Mechanism. Sci. Rep. 2020, 10, 18944. [CrossRef] [PubMed]

54. Nutiu, R.; Li, Y. Structure-Switching Signaling Aptamers. J. Am. Chem. Soc. 2003, 125, 4771-4778. [CrossRef] [PubMed]

55. Zuker, M. Mfold Web Server for Nucleic Acid Folding and Hybridization Prediction. Nucleic Acids Res. 2003, 31, 3406-3415. [CrossRef]

56. Perrier, S.; Ravelet, C.; Guieu, V.; Fize, J.; Roy, B.; Perigaud, C.; Peyrin, E. Rationally Designed Aptamer-Based Fluorescence Polarization Sensor Dedicated to the Small Target Analysis. Biosens. Bioelectron. 2010, 25, 1652-1657. [CrossRef]

57. Tang, Z.; Mallikaratchy, P.; Yang, R.; Kim, Y.; Zhu, Z.; Wang, H.; Tan, W. Aptamer Switch Probe Based on Intramolecular Displacement. J. Am. Chem. Soc. 2008, 130, 11268-11269. [CrossRef]

58. Zhu, Z.; Ravelet, C.; Perrier, S.; Guieu, V.; Fiore, E.; Peyrin, E. Single-Stranded DNA Binding Protein-Assisted Fluorescence Polarization Aptamer Assay for Detection of Small Molecules. Anal. Chem. 2012, 84, 7203-7211. [CrossRef]

59. Halperin, A.; Buhot, A.; Zhulina, E.B. On the Hybridization Isotherms of DNA Microarrays: The Langmuir Model and Its Extensions. J. Phys. Condens. Matter 2006, 18, S463. [CrossRef]

60. Fuchs, J.; Fiche, J.-B.; Buhot, A.; Calemczuk, R.; Livache, T. Salt Concentration Effects on Equilibrium Melting Curves from DNA Microarrays. Biophys. J. 2010, 99, 1886-1895. [CrossRef]

61. Buhot, A.; Pingel, J.; Fiche, J.-B.; Calemczuk, R.; Livache, T. Biophysics of DNA: DNA Melting Curve Analysis with Surface Plasmon Resonance Imaging. In Introduction to Plasmonics: Advances and Applications; Szunerits, S., Boukherroub, R., Eds.; Pan Stanford Publishing: Singapore, 2015; pp. 61-88. ISBN 978-981-4613-12-5.

62. Savitzky, A.; Golay, M.J.E. Smoothing and Differentiation of Data by Simplified Least Squares Procedures. Anal. Chem. 1964, 36, 1627-1639. [CrossRef]

63. Chovelon, B.; Fiore, E.; Faure, P.; Peyrin, E.; Ravelet, C. A Lifetime-Sensitive Fluorescence Anisotropy Probe for DNA-Based Bioassays: The Case of SYBR Green. Biosens. Bioelectron. 2017, 90, 140-145. [CrossRef] [PubMed]

64. Ruta, J.; Perrier, S.; Ravelet, C.; Fize, J.; Peyrin, E. Noncompetitive Fluorescence Polarization Aptamer-Based Assay for Small Molecule Detection. Anal. Chem. 2009, 81, 7468-7473. [CrossRef] [PubMed]

65. Perrier, S.; Guieu, V.; Chovelon, B.; Ravelet, C.; Peyrin, E. Panoply of Fluorescence Polarization/Anisotropy Signaling Mechanisms for Functional Nucleic Acid-Based Sensing Platforms. Anal. Chem. 2018, 90, 4236-4248. [CrossRef] [PubMed]

66. Zhao, Q.; Tao, J.; Uppal, J.S.; Peng, H.; Wang, H.; Le, X.C. Nucleic Acid Aptamers Improving Fluorescence Anisotropy and Fluorescence Polarization Assays for Small Molecules. Trac. Trends Anal. Chem. 2019, 110, 401-409. [CrossRef]

67. Bai, Y.; Shu, T.; Su, L.; Zhang, X. Functional Nucleic Acid-Based Fluorescence Polarization/Anisotropy Biosensors for Detection of Biomarkers. Anal. Bioanal. Chem. 2020, 412, 6655-6665. [CrossRef]

68. Fiche, J.B.; Buhot, A.; Calemczuk, R.; Livache, T. Temperature Effects on DNA Chip Experiments from Surface Plasmon Resonance Imaging: Isotherms and Melting Curves. Biophys. J. 2007, 92, 935-946. [CrossRef]

69. Fiche, J.B.; Fuchs, J.; Buhot, A.; Calemczuk, R.; Livache, T. Point Mutation Detection by Surface Plasmon Resonance Imaging Coupled with a Temperature Scan Method in a Model System. Anal. Chem. 2008, 80, 1049-1057. [CrossRef] [PubMed]

70. Pingel, J.; Buhot, A.; Calemczuk, R.; Livache, T. Temperature Scans/Cycles for the Detection of Low Abundant DNA Point Mutations on Microarrays. Biosens. Bioelectron. 2012, 31, 554-557. [CrossRef]

71. Jin, R.; Wu, G.; Li, Z.; Mirkin, C.A.; Schatz, G.C. What Controls the Melting Properties of DNA-Linked Gold Nanoparticle Assemblies? J. Am. Chem. Soc. 2003, 125, 1643-1654. [CrossRef]

72. Park, S.Y.; Gibbs-Davis, J.M.; Nguyen, S.T.; Schatz, G.C. Sharp Melting in DNA-Linked Nanostructure Systems: Thermodynamic Models of DNA-Linked Polymers. J. Phys. Chem. B 2007, 111, 8785-8791. [CrossRef] 